\title{
Uma estratégia de ensino para estimular o uso de múltiplas linguagens arquitetônicas em resposta a tecnologias digitais emergentes
}

A teaching strategy for instilling the use of multiple architectural languages in response to emerging digital technologies

Una estrategia de enseñanza para fomentar el uso de múltiples lenguajes arquitectónicos en respuesta a las tecnologías digitales emergentes

SILVA, Neander Furtado ${ }^{1}$ SILVA, Lilian Maciel ${ }^{2}$

${ }_{1}^{1}$ Programa de Pós-Graduação - PPG-FAU, Universidade de Brasília, Brasília, Brasil. neander.furtado@gmail.com ORCID: 0000-0001-8531-2852

2Programa de Pós-Graduação - PPG-FAU, Universidade de Brasília, Brasília, Brasil. lilianmfs91@gmail.com ORCID: 0000-0001-8138-7478 


\title{
Resumo
}

As novas tecnologias de projeto e de fabricação digitais têm tido um impacto reduzido na produção de uma arquitetura menos repetitiva e que explore as novas fronteiras de linguagens arquitetônicas proporcionadas por esses recursos. $O$ ensino de arquitetura desempenha um papel significativo na reprodução deste problema. Relata-se aqui uma estratégia inovadora e única de ensino que vem sendo implementada, avaliada e aperfeiçoada há aproximadamente uma década. A ênfase desta estratégia consiste na inclusão de requisitos de linguagem arquitetônica nos programas de necessidade apresentados em um certo ateliê de projeto. Foi feita uma releitura objetiva e comparativa de dois grupos de projetos obtidos em atividades desenvolvidas em sala de aula. Após vários anos de ensino nessas premissas, os resultados são promissores.

Palavras-Chave: Cliente; linguagens arquitetônicas; projeto e fabricação digitais.

\begin{abstract}
New digital design and manufacturing technologies have had little impact on the production of a less repetitive architecture that exploits the new frontiers of architectural languages provided by these resources. Architecture education plays a significant role in reproducing this problem. Here we report an innovative and unique teaching strategy that has been implemented, evaluated and improved for over a decade. The emphasis of this strategy is the inclusion of architectural language requirements in the design brief presented in a certain design studio. An objective and comparative rereading of two groups of design projects obtained in activities developed in the classroom. After several years of teaching on these premises, the results are promising.
\end{abstract}

Keywords: Client; architectural languages; digital design; digital fabrication.

\section{Resumen}

El nuevo diseño digital y las tecnologías de fabricación han tenido poco impacto en la producción de una arquitectura menos repetitiva que explota las nuevas fronteras de los lenguajes arquitectónicos proporcionados por estos recursos. La educación en arquitectura juega un papel importante en la reproducción de este problema. Aquí presentamos una estrategia de enseñanza innovadora y única que se ha implementado, evaluado y mejorado durante aproximadamente una década. El énfasis de esta estrategia es la inclusión de requisitos de lenguaje arquitectónico en los programas de necesidad presentados en cierto estudio de diseño. Se realizó una relectura objetiva y comparativa de dos grupos

de proyectos en actividades desarrolladas en el aula. Después de varios años de enseñanza en estas premisas, los resultados son prometedores.

Palabras clave: Cliente; lenguajes arquitectónicos; diseño y fabricación digitales. 


\section{Introdução}

O advento de novas tecnologias digitais na indústria da construção civil (KOLAREVIC, 2005a; KOLAREVIC, 2005b; SAKAMOTO e FERRÉ, 2008; SPILLER, 2009; IWAMOTO, 2009; SACKS et al, 2018), ocorrido nas últimas décadas, não apenas amplia o leque de possíveis soluções arquitetônicas, como também permite uma melhor satisfação das necessidades e expectativas dos clientes.

Entretanto, apesar da significativa disponibilidade dessas tecnologias, o seu uso permanece, frequentemente, limitado à reprodução de uma arquitetura utilitarista e repetitiva, sem que se explore as novas fronteiras estabelecidas por esses recursos (SILVA et al, 2009, p. 430-432).

Argumenta-se que ensino desempenha um papel significativo na reprodução deste problema. Por esta, razão, este artigo relata uma estratégia inovadora e única de ensino de ateliê de arquitetura que vem sendo implementada, avaliada e aperfeiçoada há aproximadamente uma década.

Esta estratégia se alicerça em torno de cinco princípios. Em primeiro lugar, argumenta-se que um processo de projetação deve resultar em uma proposta que satisfaça, em todos os seus aspectos, primária e essencialmente, as necessidades e expectativas do cliente e não aquelas do próprio arquiteto. Embora a importância do cliente no processo de projetação tenha sido objeto de significativa discussão (RITTEL, 1972, apud MUSTOE, 1990, p. 6; CROSS et al, 1984; LAWSON, 2005, p. 84-87), demonstrar-se-á porque este debate ainda é inconclusivo em certos aspectos e permanece como uma problemática relevante, particularmente em ensino de ateliê de projeto de arquitetura.

Em segundo lugar, argumenta-se que esta estratégia requer ao arquiteto, além das ferramentas tradicionais, o uso de instrumentos digitais de projeto (MITCHELL e MCCULLOUGH, 1995; KOLAREVIC, 2005a, p. 11-28; YESSIOS, 2005, p. 261-267; AS e SCHODEK, 2008; IBRAHIM et al, 2012; SACKS et al, 2018). Caso contrário, o conjunto de soluções arquitetônicas viáveis será restrito, repetitivo e pouco inovador.

Em terceiro lugar, considera-se que o objeto de trabalho do arquiteto não é a representação em si, mas o edifício construído (ZEVI, 1957, p. 22-27; ROBBINS, 1994, p. 10-20; AS e SCHODEK, 2008, p. 2324). Portanto, o uso dos diversos tipos de ferramentas de projeto não deve ser hierárquico. Todos são válidos a qualquer tempo, como será argumentado mais detalhadamente neste artigo.

Em quarto lugar, esta estratégia requer que o arquiteto projete levando em consideração as novas tecnologias de fabricação digital (KOLAREVIC, 2005b, p. 29-51; IWAMOTO, 2009; AGKATHIDIS e BROWN, 2013, p. 87-104; AGIRBAS, 2015, p. 319-324). Caso contrário, as soluções inovadoras se tornam raras devido às dificuldades de execução utilizando-se apenas técnicas construtivas não digitais.

Em quinto lugar, considera-se também necessário que o arquiteto projete levando em consideração o novo paradigma da customização em massa (KOLAREVIC, 2005b, p. 52-53; KOLAREVIC e KLINGER, 2008, p. 18; DINCER et al, 2014, p. 201-211; BEIRÃO et al, 2018, p. 381-390), sob pena de inviabilizar economicamente a implementação de soluções arquitetônicas inovadoras.

\section{Fundamentos, Princípios e Conceitos}

Esses cinco princípios serão descritos em maior detalhe nas sessões que se seguem. Será também detalhado como estes princípios se relacionam com a problemática e hipótese aqui apresentados.

\subsection{O Projeto de arquitetura deve satisfazer as necessidades e expectativas do cliente:}

Logan (1987) argumenta que o processo de projetação arquitetônico deve ser compreendido no âmbito das teorias de resolução de problemas. Neste sentido, Logan destaca a importância do cliente para que o próprio processo de projetação sequer venha a se iniciar e seja possível estabelecer a que necessidades responder (LOGAN, 1987, p. 20). 
Logan, assim como outros autores argumentam que o processo de formulação do problema de projeto e, por consequência, do conjunto de requisitos, emerge na realidade de forma simultânea as progressivas tentativas de solucioná-lo (RITTEL, 1972, apud MUSTOE, 1990, p. 6; LOGAN, 1987; LAWSON, 2005, p. 253-256). Portanto, o papel desempenhado pelo cliente continua essencial, não apenas para o início do processo de projeto, mas durante todo o seu desenvolvimento.

Destaque-se que cliente e usuário são conceitos distintos (LAWSON, 2005, p. 84-87). Em muitos casos o cliente também será usuário do projeto arquitetônico proposto. Em sendo assim, o arquiteto terá acesso direto ao usuário. Por outro lado, em outras situações, particularmente quanto o contratante é uma instituição ou corporação, haverá uma clara distinção entre cliente e usuário. Nestes casos, o acesso ao usuário é mais difícil. Esta questão não será aprofundada neste artigo, mas é importante enfatizar que, embora o acesso ao usuário possa ser difícil, para todo projeto de arquitetura sempre há um cliente com necessidades e expectativas específicas.

Argumenta-se que um projeto de arquitetura deve satisfazer primariamente, em todos os seus aspectos, as necessidades e expectativas do cliente e não aquelas do próprio arquiteto. Como argumenta-se a seguir, o cliente é uma "variável" frequentemente tratada de forma seletiva. Isso é particularmente observável em concursos de projeto e em ensino de ateliê de arquitetura, onde os programas de necessidade, são geralmente elaborados a priori.

Uma análise mais acurada desses programas de necessidades revela, na melhor das hipóteses, um conjunto seletivo de condicionantes. Geralmente enfatizam requisitos importantes a serem satisfeitos. Contudo, frequentemente se restringem a aspectos utilitaristas como áreas, dimensões, densidades, materiais, sistemas construtivos, organização espacial, restrições do entorno etc. Isto é observável nos programas de necessidade de concursos de projeto. Nestes requisitos precisam ser elaborados antes da contratação do arquiteto com informações claras sobre as necessidades e expectativas do cliente. Por exemplo, os programas de necessidade dos concursos de projetos Hamburg Hybrid Housing Competition (CONTROL PLUS SPACE, 2015), Taylor Wimpey 2020 Design Competition (RIBA, 2016) e Low Cost House Design Competition (COMPETITION.CC, 2020) apresentam uma série de requisitos importantes, mas todos de caráter utilitário.

Observe-se ainda que os requisitos de caráter formal, envolvendo a linguagem arquitetônica a ser adotada, ou seja, as expectativas do cliente quanto aos tipos de forma a serem utilizados, não são apresentadas.

O conceito de linguagem arquitetônica não é novo, tendo sido trabalhado por muitos (ALEXANDER et al, 1977; STINY, 1980; FLEMMING, 1989; MITCHELL, 1990, p. 83-182; BRIDGES, 1991, p. 9-16, MOUSSAVI, 2009). Adota-se aqui, como conceito de linguagem arquitetônica, o conjunto de itens de vocabulário e regras de composição destes os quais regulam a produção das formas de uma certa arquitetura em suas diversas escalas. Este conceito baseia-se particularmente nos trabalhos de Flemming (1989), Mitchell (1990), Bridges (1991) e Moussavi (2009).

A questão da formulação do programa de necessidades se torna mais crítica em ensino de ateliê de projeto. Segundo Lawson, frequentemente se presume que o ateliê de projeto nas escolas replica 0 que acontece nos escritórios dos profissionais da área. Contudo, um dos problemas constantes é que vários aspectos do mundo profissional real são difíceis de replicar nas escolas, em particular a ausência de um cliente com problemas, dúvidas, orçamentos e prazos reais. Neste caso, o professor da disciplina quase sempre assume o papel de cliente e formulador do programa de necessidades (LAWSON, 2005, p. 7).

Neste contexto, a exclusão de linguagem arquitetônica dos requisitos se torna ainda mais crítica. As possíveis motivações subjetivas desta exclusão estão fora do escopo da experiência aqui apresentada. 
Contudo, serão abordados alguns aspectos práticos deste problema.

Uma das possíveis razões para a exclusão da linguagem arquitetônica dos programas de necessidade deve-se à interpretação modernista da afirmação de Louis Sullivan de que "a forma segue a função" (SULLIVAN, 1896, apud MOUSSAVI, 2009). Moussavi argumenta que o significado pretendido por Sullivan para esta frase era mais abrangente do que aquele atribuído pelos modernistas do início do século XX. Argumenta-se aqui que este sentido restrito tem sido utilizado para defender que não se deve estabelecer requisitos relativos à forma arquitetônica, mas apenas requisitos funcionais, uma vez que a forma é consequência da função.

Argumenta-se que se esta premissa fosse verdadeira, então, para cada função se teria uma única forma. Isso é objetivamente falso. Pode-se citar três exemplos simples de artefatos, em três escalas diferentes em suporte a esta tese: 1. Na escala de ferramentas, para a mesma função "barbear", existem artefatos com formas distintas como, por exemplo, a navalha, o aparelho de barbear descartável, o barbeador elétrico, etc. 2. Na escala de mobiliário, para a função "assentar para trabalhar", existem também artefatos com formas distintas, isto é, diferentes formas de cadeiras, porém, servindo aos mesmos propósitos. 3. Na escala arquitetônica, pode-se citar o resultado de um mesmo concurso de projetos, onde diversas soluções formais, para um mesmo programa de necessidades, são frequentemente aprovadas pelo júri. Portanto, a visão restrita e utilitarista de que "a forma segue a função" não subsiste.

Uma outra possível causa da exclusão de requisitos de linguagem arquitetônica dos programas de necessidade talvez se deva a tentativa de se igualar a arquitetura a outros tipos arte. Nestas artes, a escolha dos requisitos da forma é considerada prerrogativa do autor da obra e não do cliente. Ainda que se presuma que a arquitetura seja de fato uma forma de arte, há que se considerar qual a extensão real das similaridades e quais as principais diferenças em relação a outros tipos de arte.

A arquitetura difere de quase todas as outras artes em pelo menos um aspecto objetivamente observável. Por exemplo: um pintor produz sua obra de arte antes de encontrar um cliente. Então alguém que vem a conhecer o produto e que passa a apreciá-lo se torna cliente do pintor ao adquiri-lo. Em arquitetura, muito raramente $o$ arquiteto concebe um projeto para si próprio. Na vasta maioria das situações projetuais não há produto antes de se obter um cliente, como já argumentado. O cliente vem primeiro e o projeto proposto deve satisfazer seus requisitos e expectativas.

Uma outra possível razão de se adotar a mesma linguagem arquitetônica em projetos diferentes é o argumento da homogeneidade por vizinhança. Neste caso, defende-se que um novo projeto deve adotar uma linguagem compatível com a vizinhança na qual estará inserido. Reconhece-se que este é um argumento válido para a preservação de cidades ou tecidos urbanos cujo valor histórico determina a própria razão de ser e a economia da população local. Contudo, entende-se aqui que se o princípio da homogeneidade por vizinhança for aplicado a todas as situações de projeto, não haverá, por indução, mais inovação arquitetônica.

Assim sendo, será descrita aqui uma estratégia para estimular a compreensão de que o projeto de arquitetura é essencialmente para o cliente. Um arquiteto deve estar preparado para trabalhar com uma gama de opções que vão além de suas próprias preferências particulares, inclusive em termos de linguagens arquitetônicas.

\subsection{O futuro arquiteto deve, além das ferramentas tradicionais, fazer uso indispensavelmente de instrumentos digitais de projeto:}

Argumenta-se que o advento das ferramentas digitais de projeto não significou a completa abolição dos instrumentos anteriormente existentes. Contudo, é inegável que estes novos recursos vieram ampliar, significativamente, o leque de possíveis soluções arquitetônicas (MITCHELL, 2001, p. 352- 
363), particularmente a modelagem tridimensional digital, as animações computacionais, as renderizações foto realistas e os ambientes virtuais e interativos (AS e SCHODEK, 2008, p. 25, 66-88).

Dentre estes, a modelagem tridimensional digital tornou possível a criação de formas arquitetônicas mais complexas do que aquelas predominantes até meados da década de noventa (AS e SCHODEK, 2008 , p. $6,134,138)$. Até então, as formas mais frequentes eram geralmente composições de planos retangulares paralelos ou perpendiculares entre si, como por exemplo, o Toronto-Dominion Centre de Mies van der Rohe, cuja construção foi concluída em 1991 (Figura 01).

Figura 01: Toronto-Dominion Centre de Mies van der Rohe, 1991.

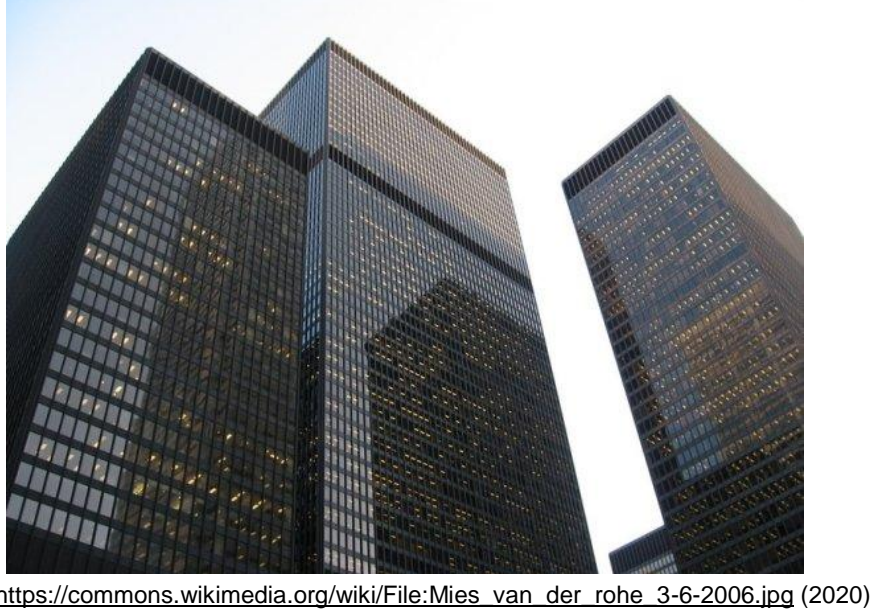

Os limites da geometria das soluções arquitetônicas poderiam, no máximo, admitir formas curvas compostas por segmentos e seções de arco extrudadas ao longo de um único eixo do sistema cartesiano, como por exemplo, o Edifício Copan, de Niemeyer, de 1966 (Figura 02).

Figura 02: Edifício Copan, de Niemeyer, 1966.

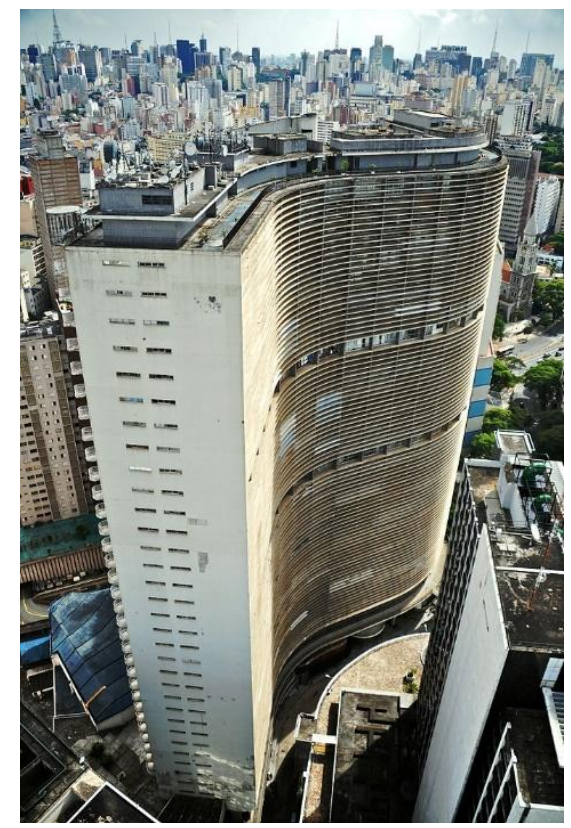

Fonte: Silvio Tanaka (https://pt.wikipedia.org/wiki/Ficheiro:Copan_ST.jpg, 2020)

As razões principais para a adoção destes limites de formas eram os custos relativos ao tempo de concepção e desenvolvimento de projetos, bem como os custos de sua construção.

A modelagem tridimensional digital tornou possível conceber, de maneira intuitiva e rápida, formas 
compostas por polígonos irregulares e que se interceptam de forma predominantemente não paralela e não perpendicular, como, por exemplo, o Museu de Arte de Tel Aviv de Scott Preston Cohen, de 2004 (Figura 03).

Figura 03: Museu de Tel Aviv, de Scott Preston Cohen, 2004.

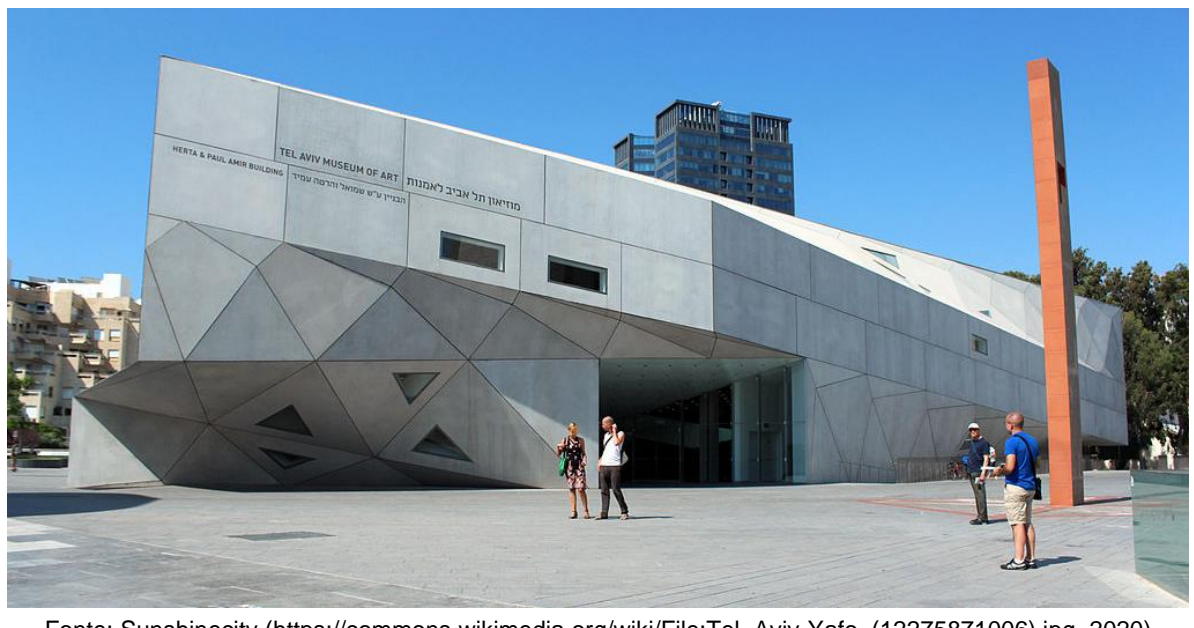

Fonte: Sunshinecity (https://commons.wikimedia.org/wiki/File:Tel_Aviv-Yafo_(12275871006).jpg, 2020)

A modelagem tridimensional digital tornou viável também a concepção de formas resultantes da propagação de curvas do tipo NURBS (KOLAREVIC, 2005a, p. 15-17) ao longo de percursos igualmente curvos. Isso possibilitou a geração de superfícies que anteriormente eram de difícil representação e dispendiosas pelo tempo necessário para produzi-las. Um exemplo disso é o Heydar Aliyev Center de Zaha Hadid, de 2012, no Azerbaijão (Figura 04).

Figura 04: Aliyev Center de Zaha Hadid, de 2012, no Azerbaijão.

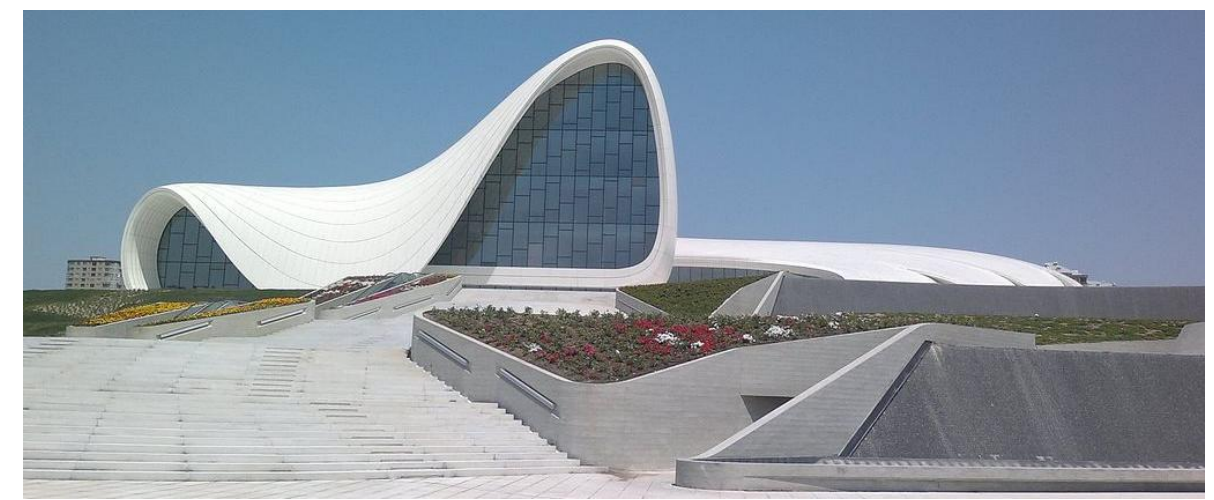

Fonte: Interfase (https://upload.wikimedia.org/wikipedia/en/thumb/d/d3/Heydar_Aliyev_Cultural_Center.jpg/1024pxHeydar_Aliyev_Cultural_Center.jpg, 2020)

Estas formas não são necessariamente impossíveis de serem concebidas e representadas com ferramentas não digitais. Entretanto, as dificuldades técnicas e o tempo necessário para isso é extremamente maior, inviabilizando o seu uso na projetação arquitetônica (AS e SCHODEK, 2008, p. 138).

Além disso, deve-se observar que a modelagem tridimensional digital possibilita percepções, apreciações e avaliações impossíveis de serem feitas por meio de recursos não digitais. Tome-se como exemplo disso um mesmo projeto representado em um modelo físico reduzido (maquete) e em um modelo tridimensional digital. Se a maquete possibilita, por um lado, recursos táteis e gravitacionais nem sempre disponíveis no modelo tridimensional digital, ela, entretanto, somente pode ser observada de fora. Apenas o modelo tridimensional digital permite realizar uma caminhada virtual através do projeto proposto, possibilitando a percepção da arquitetura em tempo real e no espaço em escala 
humana (AS e SCHODEK, 2008, p. 117-129, 140).

A modelagem tridimensional digital é hoje predominantemente paramétrica (BRIDGES, 1991, p.7-8; WOODBURY, 2010, p. 11-47). Representações paramétricas são aquelas que descrevem os objetos como um conjunto de relações variáveis e não como artefatos de dimensões ou propriedades fixas. Isto resulta em um conjunto de vários tipos, categorias ou famílias de artefatos dos quais pode-se derivar um número praticamente ilimitado de aplicações específicas.

Argumenta-se que existem atualmente dois paradigmas principais em modelagem tridimensional paramétrica. Um não é melhor do que o outro. Ambos são essenciais ao processo de projetação. São duas maneiras complementares de se projetar. O primeiro deles é orientado aos processos de criação das formas (por exemplo, extrusão, revolução, operações booleanas, malhas, subdivisões, superfícies regradas, superfícies curvas racionais não uniformes - NURBS etc.). Programas que mantêm um registro do processo de criação das formas, mesmo depois de sua geração, permitindo a sua pós edição, baseiam-se neste tipo de parametria. Rhinoceros (McNeel \& Associates), formZ (AutoDesSys) e 3D Studio Max (Autodesk) baseiam-se, predominante, mas não exclusivamente, neste tipo de paradigma.

O segundo paradigma é orientado à função que os componentes construtivos vão desempenhar na edificação (por exemplo, laje, pilar, viga, parede, porta, janela, escada etc.), suas interrelações e suas propriedades. Este é o paradigma denominado Building Information Modeling - BIM. Programas como ArchiCAD (Graphisoft), Revit (Autodesk) e OpenBuildings Designer (Bentley) baseiam-se, predominante, mas não exclusivamente, neste tipo de parametria.

\subsection{A representação não é o objeto de trabalho do arquiteto e uso dos diversos tipos de ferramentas de projeto não deve ser hierárquico:}

Muitos arquitetos utilizam a palavra representação geralmente se referindo às etapas finais do processo de projetação nas quais, tendo sido tomada a maioria das decisões, resta apenas produzir documentos que apresentem o projeto aos órgãos de aprovação ou instruam a sua construção.

O conceito de representação adotado é mais abrangente. Neste sentido representação é o uso de símbolos ou coisas como substitutos de outras coisas (MITCHELL, p. 11, 1995). Por exemplo, quando um texto é escrito se está representando ou substituindo os sons das palavras pela escrita. De maneira semelhante, um músico está representando quando utiliza os símbolos da pauta musical em substituição aos sons e ao ritmo da música.

O escritor utiliza a linguagem escrita porque precisa de um meio de registro mais duradouro do que a linguagem oral. Além disto, sua mente não é capaz de registrar tudo em detalhe, com precisão e em grande quantidade por um tempo significativo. O escritor também precisa da representação escrita para poder conceber, avaliar e desenvolver o seu trabalho antes da impressão final.

O arquiteto recorre a diversas formas de representação. Não é possível projetar sem representar. Embora as ideias nasçam em sua mente, as mesmas só podem ser concebidas e desenvolvidas plenamente quando se utiliza algum sistema de representação.

Um arquiteto está representando quando utiliza croquis, em substituição a suas ideias iniciais de projeto. Da mesma forma, o arquiteto também está representando quando utiliza modelos reduzidos em substituição às soluções arquitetônicas que pretende ver construídas.

Tudo aquilo que for utilizado em substituição às ideias, proposições e soluções arquitetônicas, que se pretenda construir, constitui-se em representação: o croqui, a maquete física de estudo, as plantasbaixas, os cortes, as elevações, os modelos virtuais, os protótipos rápidos, a maquete de apresentação final etc. 
Considera-se aqui que o objeto de trabalho do arquiteto não é a representação em si, qualquer que seja o instrumental utilizado, mas o edifício construído. A representação não deve ser considerada o produto final do trabalho do arquiteto, sob pena de se perder de vista como a obra edificada pode vir a ser.

Zevi argumenta que as representações ortográficas foram desenvolvidas para viabilizar a construção e não para a perfeita compreensão do conjunto de espaços propostos. Ele argumenta também que, mesmo representações mais próximas do mundo real, como a perspectiva, ainda se constitui em uma redução da realidade. Zevi afirma que somente o edifício construído pode proporcionar uma verdadeira compreensão e apreensão da arquitetura (ZEVI, 1957, p. 22-27).

Segundo Robbins, o advento da profissão de arquiteto precedeu ao desenvolvimento das técnicas de representação gráfica (ROBBINS, 1994, p. 10-20). Portanto, o objetivo do arquiteto não é produzir representações, mas edifícios.

Imdat As e Schodek caracterizam o trabalho do arquiteto como uma "obra de arte de dois estágios", ou seja, aquela que é sempre produzida através do uso de uma etapa intermediária, a representação, mas que inevitavelmente leva ao trabalho final, o edifício (AS e SCHODEK, 2008, p. 23-24).

$\mathrm{Na}$ experiência aqui relatada, todas formas de representação são permitidas a qualquer tempo: o croqui, a maquete física de estudo, as plantas-baixas, os cortes, as elevações, os modelos virtuais, as animações solares, os protótipos rápidos, a maquete de apresentação final etc.

Isto não significa que novos recursos não possam substituir ferramentas mais antigas. Por exemplo, edifícios predominantemente não retangulares estão se tornando cada vez mais comuns na arquitetura contemporânea. O Memorial Darcy Ribeiro, de João Filgueiras Lima no campus principal da Universidade de Brasília é um bom exemplo disso.

Outro caso, bastante conhecido internacionalmente, o Guggenheim de Bilbao, de Frank Gehry, ilustra de forma muito clara as limitações das projeções ortográficas, tanto em apresentar o projeto, quanto em instruir a sua construção.

Nestes casos, a representação por projeções ortográficas se torna insuficiente. Plantas-baixas e cortes foram produzidas para estes projetos. Contudo, esses documentos desempenharam um papel reduzido na concepção e na construção desses edifícios. Seu papel se limitou principalmente a locação da obra no sítio e a satisfazer as exigências das autoridades responsáveis pela aprovação dos projetos e dos órgãos fiscalizadores do exercício profissional.

A construção do Guggenheim de Bilbao, assim como a do Memorial Darcy Ribeiro na UnB, só foi possível graças a utilização de modelos tridimensionais digitais ligados diretamente a tecnologias de fabricação digital. Isto implicou em novas formas de documentação de projeto que foram utilizadas e exploradas na experiência descrita neste artigo.

As ferramentas digitais vêm ganhando terreno na projetação arquitetônica nas últimas décadas, substituindo alguns instrumentos mais antigos e oferecendo novas possibilidades. Entretanto, é garantida a livre escolha de qual ferramenta utilizar ao longo da projetação porque diversos tipos de representação frequentemente desempenham papeis mutualmente complementares. $O$ uso de um número significativo de múltiplas ferramentas permite manter o foco na obra a ser edificada e evitar o risco de se enamorar por um tipo de representação em particular.

Portanto, o uso dos diversos tipos de ferramentas de projeto na experiência relatada aqui é não hierárquico. A mesma importância é dada a todos os tipos de ferramentas e mídias de projeto. Por exemplo, ferramentas como lápis e papel são permitidos, mas não são os únicos a serem utilizados. 
Além disso, não é obrigatório iniciar o projeto com estes instrumentos e mídias. Os computadores são ferramentas necessárias e podem, se escolhidos, ser utilizados desde o início do processo de projetação. Em certos casos se tornam essenciais, porque sem eles o segundo e o terceiro projetos da experiência aqui relatada não são viáveis de serem concebidos ou construídos.

\section{4. $O$ arquiteto deve projetar necessariamente levando em consideração as novas tecnologias de fabricação digital:}

A relação entre projeto de arquitetura e construção foi, até meados dos anos 90 , caracterizada pelo envio de desenhos técnicos em papel ao canteiro de obras. O conteúdo destes desenhos eram, em sua quase totalidade, projeções ortográficas.

A partir do final dos anos 90, passa a se tornar cada vez mais comum, um novo procedimento: a fabricação digital (KOLAREVIC, 2005b, p. 29-51; IWAMOTO, 2009; AGKATHIDIS e BROWN, 2013, p. 87-104; AGIRBAS, 2015, p. 319-324). Os avanços nas técnicas de representação de modelos digitais permitem hoje utilizá-los para fabricar componentes construtivos diretamente a partir de arquivos enviados às fábricas pelos próprios arquitetos. Por outro lado, os canteiros de obra vêm se tornando gradativamente em locais de montagem final destes componentes e subsistemas produzidos nas fábricas.

Portanto, o ensino de ateliê de arquitetura deve levar em consideração a fabricação digital. Sem isso as soluções inovadoras se tornam raras devido às dificuldades de execução utilizando-se apenas técnicas construtivas não digitais.

\section{5. $O$ arquiteto deve projetar levando em consideração o novo paradigma da customização em massa:}

A indústria da construção tem se baseado na produção em massa de componentes padronizados. Estes são produzidos, em escala, em uma gama limitada de formas e tamanhos, até que venham a resultar em uma combinação de elementos em uma fábrica ou sejam transformados em parte do edifício no canteiro de obras (referência omitida para preservar avaliação cega).

Entretanto, as novas técnicas de fabricação digital não apenas automatizaram a produção serial, em larga escala, mas também possibilitaram uma mudança fundamental no tipo de produto: em aparente paradoxo, hoje é possível produzir, por exemplo, 1.000 artefatos diferenciados pelo mesmo custo de 1.000 artefatos idênticos (KOLAREVIC, 2005b, p. 52.; KOLAREVIC e KLINGER, 2008, p. 18).

A fabricação digital possibilita uma mudança de paradigma na arquitetura contemporânea: a customização em massa. Esta permite que os elementos construtivos sejam produzidos para propósitos específicos, para se tornarem em elementos singulares em contextos únicos de projeto arquitetônicos (SILVA et al, 2009, p. 430).

As implicações disto em arquitetura são profundas. A produção manufaturada não mais significa a produção em massa de um item padronizado para servir a todos os propósitos. Agora pode-se customizar em massa, trazendo os benefícios da produção em escala à fabricação de componentes únicos e diferenciados por variações digitalmente controladas. Portanto, sob o paradigma da customização em massa rompem-se os limites de linguagem arquitetônica definidos há um século atrás (referência omitida para preservar avaliação cega).

Assim, considera-se também necessário que o ensino da projetação considerando este novo paradigma, sob pena de inviabilizar economicamente a implementação de soluções arquitetônicas realmente inovadoras. 


\section{Problemática}

As novas tecnologias de projeto e de fabricação digitais têm tido um impacto reduzido na produção de uma arquitetura menos repetitiva. Isso também é evidente no que concerne às linguagens arquitetônicas adotadas. Por mais que se diga que a forma é secundária e que os outros aspectos de caráter utilitário da arquitetura são mais importantes, a forma da edificação é o primeiro elemento a ser notado e comentado pelo cliente. Se o projeto do arquiteto não for aprovado pelo cliente na avaliação da linguagem arquitetônica, nenhum dos outros aspectos do projeto será sequer examinado ou poderá compensar essa deficiência.

Os programas de necessidade apresentados nos ateliês de projeto geralmente excluem requisitos de linguagem arquitetônica, conforme demonstrado anteriormente. Isso resulta na formação de arquitetos que concebem e desenvolvem projetos que não atendem a expectativas consideradas muito importantes por muitos clientes em potencial. Além disso, esses profissionais tendem a propor projetos que adotam uma única linguagem arquitetônica, reduzindo suas oportunidades de trabalho e tornando o seu impacto social significativamente menor. Acrescente-se que poucos tiram partido das novas possibilidades formais proporcionadas pelas novas tecnologias digitais de projeto, fabricação e construção.

Portanto, a questão principal que aqui se apresenta é: como estimular, no ensino de ateliê de projeto, o uso de múltiplas linguagens arquitetônicas em resposta às tecnologias digitais emergentes e para que as necessidades e expectativas do cliente quanto à linguagem arquitetônica sejam também atendidas?

\section{Hipótese}

Acredita-se que a adoção de mais de uma tarefa de projeto nas disciplinas de ateliê, pressupondo-se que seriam para clientes hipotéticos distintos, juntamente com a inclusão de condicionantes de linguagens arquitetônicas específicas para cada um deles, constitui-se na resposta mais promissora à questão apresentada na sessão anterior.

\section{Procedimentos Metodológicos}

A proposta descrita acima foi implementada e testada incluindo condicionantes com regras definidoras da forma nos programas de necessidades de cada uma das tarefas de projeto. A abordagem adotada é pragmática, envolvendo apenas descrições de formas e regras de composição, devido à curta duração do semestre letivo e ao fato do ateliê de projeto em questão estar próximo do início do curso. Três pequenos projetos arquitetônicos são produzidos em terreno próximo a um lago artificial: um escritório, um restaurante e um pavilhão de exposições. O programa de necessidades inclui, para cada um desses projetos, requisitos de forma, função, construção e ambiente.

Os requisitos de forma são diferentes para cada projeto. O escritório é uma composição de planos retangulares paralelos ou perpendiculares entre si, como ocorre, por exemplo, na casa de Schröder, de Gerrit Rietveld, de 1924, em Utrecht, Holanda (Figura 05). 
Figura 05: A casa de Schröder de Gerrit Rietveld em Utrecht.

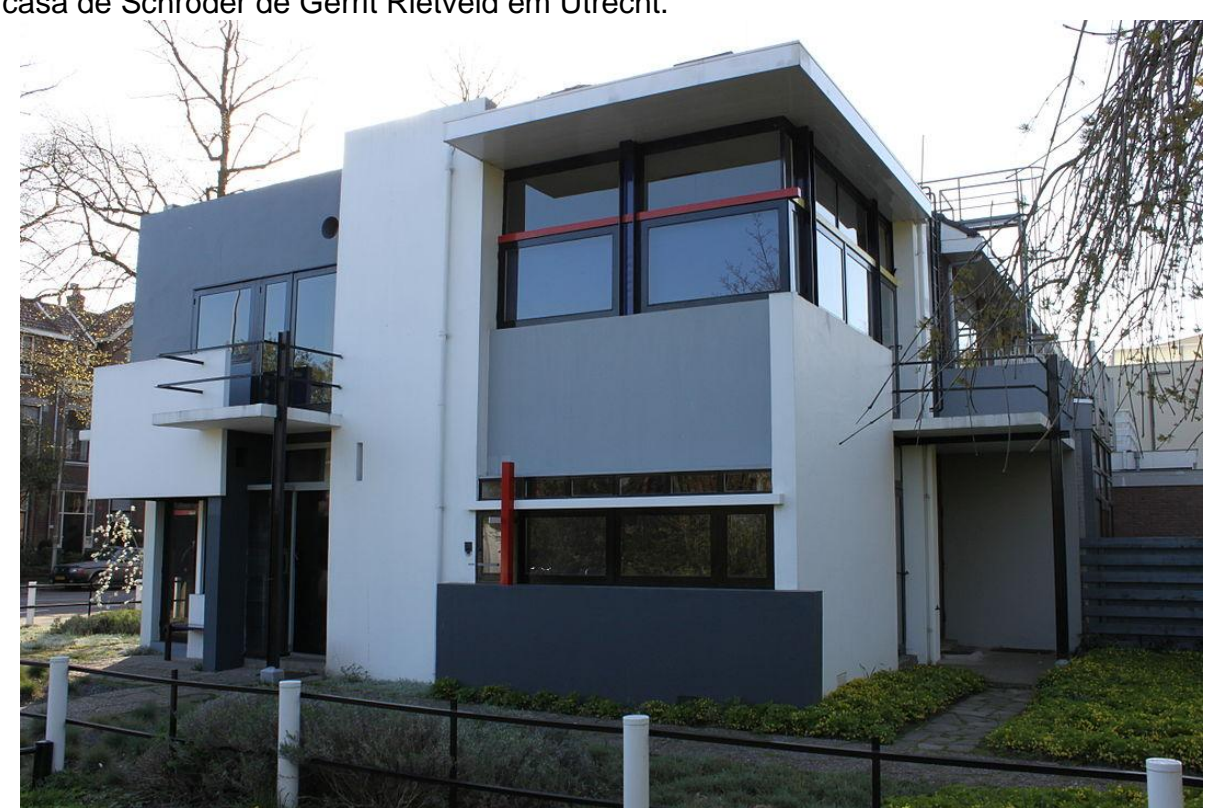

Fonte: Husky - Own work, CC BY 3.0, https://commons. wikimedia.org/w/index.php?curid=10042368 (2020)

O restaurante é definido por uma envoltória composta de planos predominantemente não retangulares, não paralelos e não perpendiculares entre si, como, por exemplo, o restaurante Boos Beach Club, projeto de Metaform Architects, de 2016, em Luxemburgo (Figura 06).

Figura 06: Restaurante Boos Beach Club por Metaform Architects em Luxemburgo.

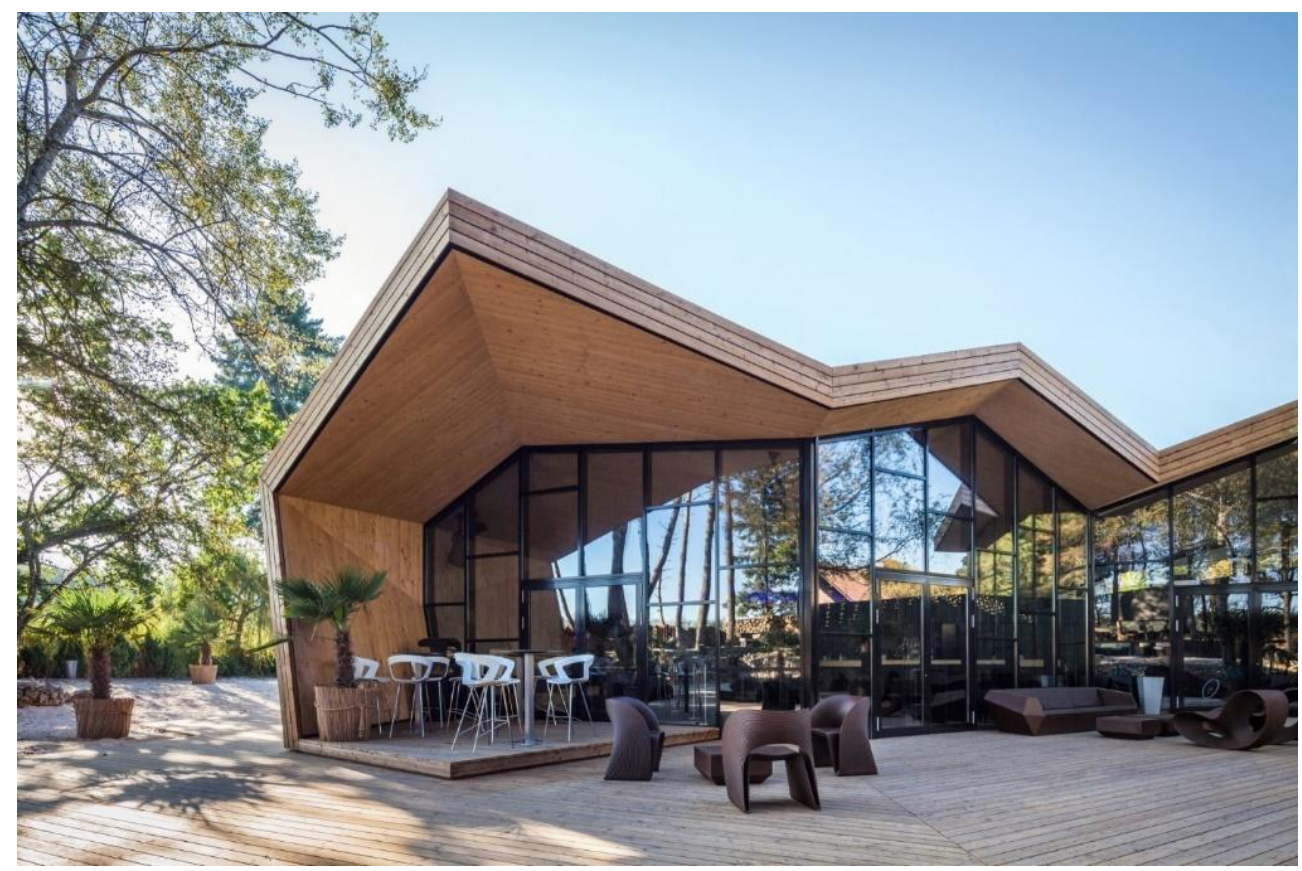

Fonte: Steve Troes, https://www.archdaily.com/797466/boos-beach-club-restaurant-metaformarchitects?ad_source=search\&ad_medium=search_result_all (2020).

A forma do pavilhão de exposições é circunscrita por envoltória composta predominantemente por uma ou mais superfícies curvilíneas e contínuas, como, por exemplo, no Museu Riverside, de Zaha Hadid Architects e BuroHappold Engineering, de 2011, em Glasgow, Reino Unido (Figura 07). 
Figura 07: Museu Riverside de Zaha Hadid Architects e BuroHappold Engineering, em Glasgow, Reino Unido.

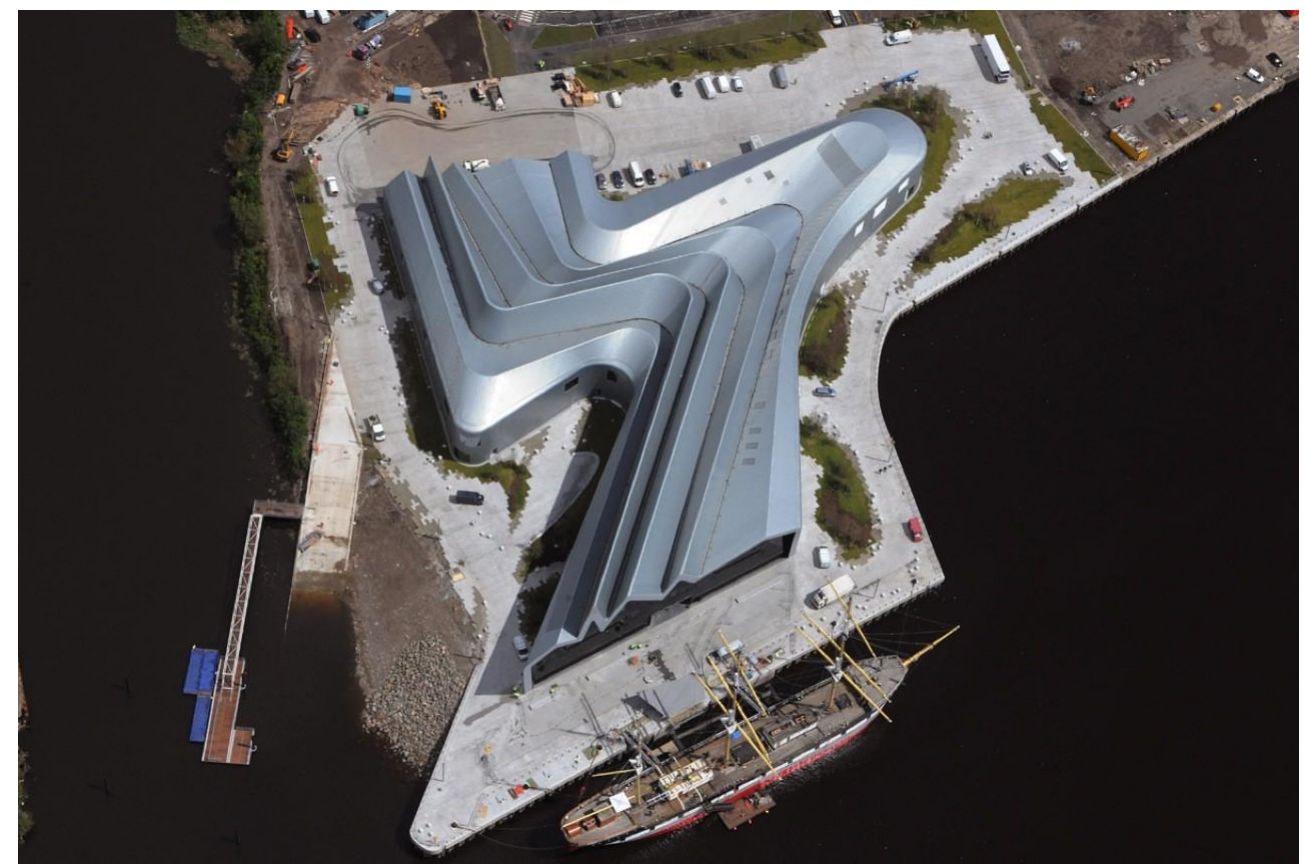

Fonte: https://www.archdaily.com/161343/over-500000-visitors-to-the-riverside-museum-in-its-first-weeks/501557d528ba0d02f0000e6a-over500000-visitors-to-the-riverside-museum-in-its-first-weeks-photo (2020).

Os aspectos formais das edificações são enfatizados, sem, contudo, deixar de analisar os aspectos funcionais, ambientais e construtivos. Em todos os projetos foram solicitadas análises que envolvessem todos estes aspectos.

A experiência aqui descrita envolveu também a integração do ateliê de projeto em questão com o conteúdo de disciplina em modelagem tridimensional digital ministrada no mesmo semestre.

O Quadro 01 a seguir, apresenta os quatro grupos de condicionantes de cada um dos três projetos da experiência descrita neste artigo.

Quadro 01: condicionantes de projeto.

\begin{tabular}{|c|c|c|c|c|}
\hline \multirow[t]{2}{*}{ Projeto/Tema } & \multicolumn{4}{|c|}{ Condicionantes } \\
\hline & Formais & Funcionais & Construtivos & Ambientais \\
\hline $\begin{array}{l}1 \text { Edifício } \\
\text { administrativo }\end{array}$ & $\begin{array}{l}\text { Solução formal } \\
\text { baseada em } \\
\text { predominantemente } \\
\text { em composição de } \\
\text { planos retangulares } \\
\text { paralelos ou } \\
\text { perpendiculares } \\
\text { entre si. }\end{array}$ & $\begin{array}{l}\text { Localização livre a uma } \\
\text { distância mínima de } 30 \\
\text { metros da orla. } \\
\text { - Recepção / secretaria } \\
\text { (9 a } 12 \text { m2); Sala de } \\
\text { trabalho para } 1 \text { pessoa } \\
\text { (12 a } 15 \text { m2); Sanitário } \\
\text { (2,5 a } 4 \text { m2); Despensa } \\
\text { (3 a } 4 \text { m2); Área total } \\
\text { máxima: } 45 \text { m2 }\end{array}$ & $\begin{array}{l}\text { Sistemas e componentes } \\
\text { construtivos pré- } \\
\text { moldados / pré- } \\
\text { fabricados. Componentes } \\
\text { construtivos de funções } \\
\text { específicas (pilares, } \\
\text { vigas, lajes e vedações). }\end{array}$ & $\begin{array}{l}\text { Orientação solar } \\
\text { e aspectos } \\
\text { naturais do } \\
\text { terreno. }\end{array}$ \\
\hline 2 Restaurante & $\begin{array}{l}\text { Solução formal } \\
\text { baseada em uma } \\
\text { envoltória composta } \\
\text { de planos } \\
\text { predominantemente } \\
\text { não retangulares, } \\
\text { não paralelos e não } \\
\text { perpendiculares } \\
\text { entre si. }\end{array}$ & $\begin{array}{l}\text { Localização na orla, a } \\
\text { uma distância mínima } \\
\text { de } 30 \text { metros. } \\
\text { - Bancada de } \\
\text { atendimento ( } 6 \text { a } 8 \\
\text { metros lineares); Área } \\
\text { de preparo (9 a } 12 \text { m2); } \\
\text { Área para mesas (30 a } \\
40 \text { m2); Sanitários } \\
\text { masculino e feminino }\end{array}$ & $\begin{array}{l}\text { Sistemas e componentes } \\
\text { construtivos pré- } \\
\text { moldados / pré- } \\
\text { fabricados e } \\
\text { componentes } \\
\text { customizados. Sugere-se } \\
\text { que a envoltória tenha } \\
\text { funções apenas de } \\
\text { vedação e seja } \\
\text { suportada por estrutura }\end{array}$ & $\begin{array}{l}\text { Orientação solar } \\
\text { e aspectos } \\
\text { naturais do } \\
\text { terreno. }\end{array}$ \\
\hline
\end{tabular}




\begin{tabular}{|c|c|c|c|c|}
\hline & & $\begin{array}{l}\text { (16 m2 no mínimo, } \\
\text { cada); Área total } \\
\text { máxima: } 100 \mathrm{~m} 2\end{array}$ & $\begin{array}{l}\text { tubular ou perfilada } \\
\text { independente. }\end{array}$ & \\
\hline $\begin{array}{l}3 \text { Pavilhão de } \\
\text { exposições }\end{array}$ & $\begin{array}{l}\text { Solução formal } \\
\text { baseada em } \\
\text { envoltória composta } \\
\text { predominantemente } \\
\text { por uma ou mais } \\
\text { superfícies } \\
\text { curvilíneas e } \\
\text { contínuas. }\end{array}$ & $\begin{array}{l}\text { Localização livre a uma } \\
\text { distância mínima de } 30 \\
\text { metros da orla. } \\
\text { - } 10 \text { a } 14 \text { metros } \\
\text { lineares de paredes } \\
\text { para exposição de } \\
\text { quadros; área de } 150 \text { a } \\
200 \text { m2 para exposição } \\
\text { de esculturas e } \\
\text { instalações de caráter } \\
\text { artístico; Sanitários } \\
\text { masculino e feminino } \\
\text { com } 2 \text { boxes cada, } \\
\text { sendo um para } \\
\text { deficiente (16 m2 no } \\
\text { mínimo, cada). Área } \\
\text { total máxima: } 400 \text { m2 }\end{array}$ & $\begin{array}{l}\text { Sistemas e componentes } \\
\text { construtivos } \\
\text { customizados em massa. } \\
\text { Sugere-se que a } \\
\text { envoltória tenha funções } \\
\text { apenas de vedação e } \\
\text { seja suportada por } \\
\text { estrutura independente } \\
\text { composta por grelha do } \\
\text { tipo "egg crate". }\end{array}$ & $\begin{array}{l}\text { Orientação solar } \\
\text { e aspectos } \\
\text { naturais do } \\
\text { terreno. Evitar a } \\
\text { incidência solar } \\
\text { direta sobre } \\
\text { áreas com } \\
\text { material } \\
\text { exposto. }\end{array}$ \\
\hline
\end{tabular}

Duas ferramentas de modelagem tridimensional paramétrica vêm sendo utilizadas. A primeira delas é um modelador orientado predominantemente aos processos de criação das formas (formZ, AutoDesSys). O outro modelador é orientado predominantemente à função que os componentes construtivos vão desempenhar na edificação, ou seja, um sistema BIM (ArchiCAD, Graphisoft).

Ao longo de cada projeto é recomendado o uso da ferramenta que permita alcançar o objetivo de cada tarefa projetual de forma mais intuitiva e rápida. Para facilitar, foram desenvolvidos protocolos sugestivos de utilização dessas ferramentas digitais para cada um dos três processos de projetação:

- Edifício administrativo: 1. formZ (modelo do terreno); 2. ArchiCAD (2.1 Modelo do edifício completo; 2.2 Inserção de objetos; 2.3 Pranchas com projeções ortográficas; 2.4 Renderizações); 3. formZ (Animação solar).

- Restaurante: 1. formZ (1.1 Laje de piso térreo; 1.2 Envoltória não ortogonal; 1.3 Lajes intermediárias; 1.4 Paredes verticais irregulares; 1.5 Aberturas irregulares; 1.6 Estrutura preferencialmente tubular; 1.7 Plano de corte da envoltória; 1.8 Impressão; 1.9 Maquete volumétrica); 2. ArchiCAD (2.1 Transformação de paredes verticais e lajes em objetos BIM; 2.2 Inserção de portas e janelas padronizadas; 2.3 Inserção de objetos); 3. formZ (Animação solar).

- Pavilhão de exposições: 1. formZ (1.1 Laje de piso térreo; 1.2 Envoltória curvilínea; 1.3 Lajes intermediárias; 1.4 Paredes Verticais irregulares; 1.5 Aberturas irregulares; 1.6 Estrutura preferencialmente em grelha ortogonal; 1.7 Plano de corte da estrutura em grelha, optativo; 1.8 Animação solar) 2. ArchiCAD (2.1 Inserção de portas e janelas padronizadas; 2.2 Inserção de objetos).

Estes protocolos serão apresentados de forma mais detalhada em publicação futura, tendo em vista as limitações de espaço aqui estabelecidas.

\section{Avaliação e Discussão dos Resultados Obtidos}

O objetivo principal da estratégia de ensino descrita neste artigo era estimular o uso de múltiplas linguagens arquitetônicas para que as necessidades e expectativas do cliente fossem atendidas também neste aspecto. 
Os resultados utilizados para efeitos da avaliação aqui descrita foram exclusivamente aqueles trabalhos, do ponto de vista objetivo, que já se encontravam de posse do primeiro autor deste artigo e foram obtidos, ao longo de 12 anos, em função de atividades desenvolvidas em sala de aula. Apenas os arquivos digitais já de posse do primeiro autor foram utilizados, não tendo sido realizada nenhuma coleta nova de dados. Não foram aplicados questionários aos autores dos projetos, nem foi realizado qualquer outro tipo de contato com eles. Foram avaliados apenas as formas dos projetos em si, sem levar em consideração a identidade dos autores e o perfil sócio-econômico-cultural de cada um deles. $\mathrm{Na}$ avaliação comparativa dos projetos em si, foi considerada apenas a descrição objetiva das linguagens arquitetônicas contidas nos planos de cursos da disciplina de ateliê de projeto em questão.

Os critérios objetivos para classificação das formas foram baseados na argumentação anteriormente apresentada na sessão 2.2 e ilustrada pelas Figuras 01 a 04, as quais estabelecem categorias formais ou de linguagens arquitetônicas. As Figuras 05,06 e 07 da sessão 5 correspondem às mesmas categorias representadas pelas Figuras 01, 03 e 04, respectivamente.

Inicialmente foram comparados trabalhos de dois grupos distintos de produtos: o primeiro deles continha sequências de projetos realizados em dois semestres letivos antes da inclusão de requisitos de linguagem arquitetônica no programa de necessidades. Estes semestres foram designados 'Sem. 1a' e 'Sem. 1b'. O segundo grupo continha sequências de projetos realizados em dois semestres letivos depois da inclusão de requisitos de linguagem arquitetônica no programa de necessidades. Estes semestres foram designados 'Sem. 2a' e 'Sem. 2b'. A Figura 08 mostra estes primeiros resultados.

Figura 08: Percentual de sequências de projetos utilizando linguagens diferentes ou únicas em todos os projetos de cada sequência.

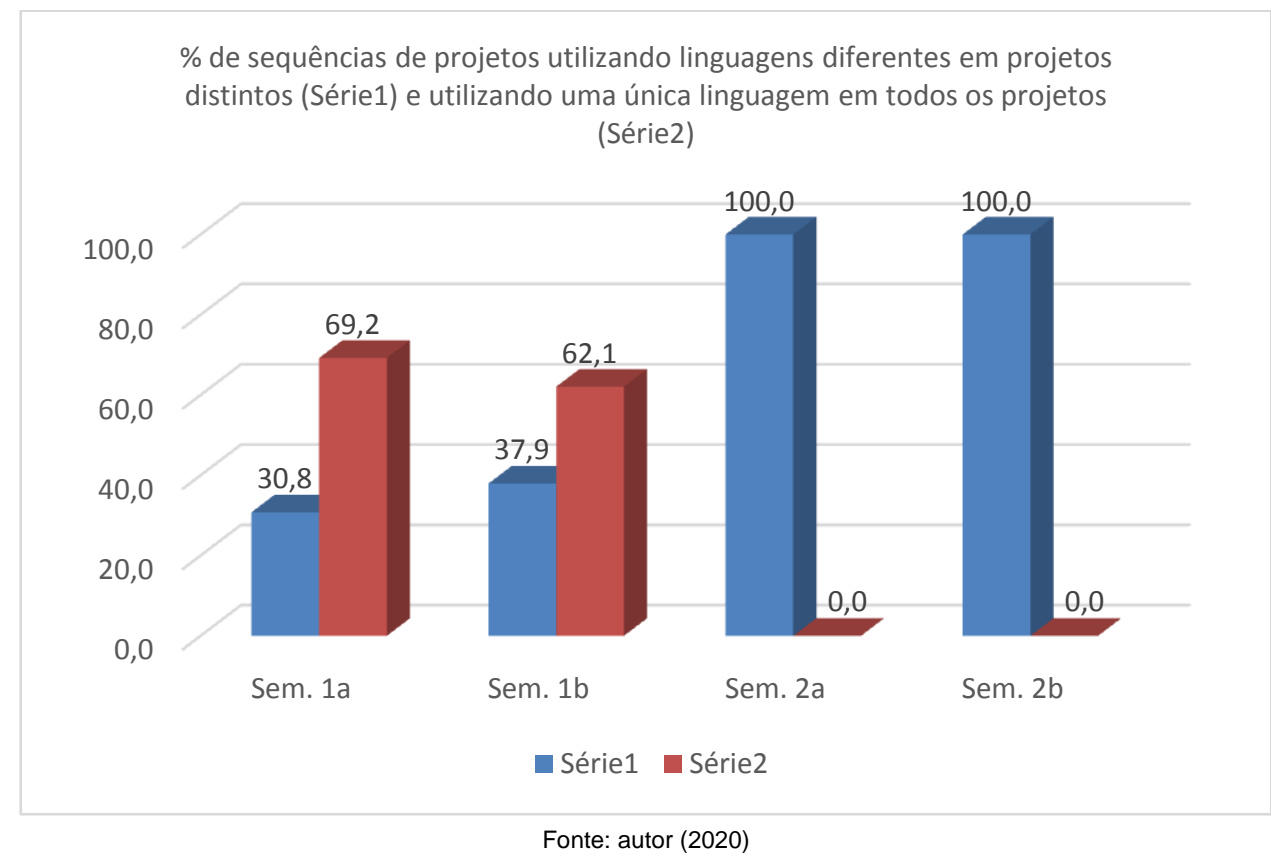

Portanto, observa-se que o número relativo de sequências de projetos utilizando linguagens diferentes em projetos distintos aumentou significativamente. Em seguida, os mesmos dois grupos acima descritos foram comparados com base na seguinte pergunta: quantos projetos foram produzidos utilizando composições de planos irregulares, não perpendiculares e não paralelos ou composições de uma ou mais superfícies curvilíneas (nas categorias representadas pelas Figuras 03 e 06 e Figuras 04 e 07)? Em outras palavras, estas duas categorias de formas representam aquelas que se tornaram viáveis com o advento das tecnologias digitais de projeto e de fabricação. As categorias de formas ilustradas pelas Figuras 01, 02 e 05 representam os limites geométricos predominantes na arquitetura 
anterior a era digital. A Figura 09 mostra estes resultados.

Figura 09: Limites de complexidade das formas dos projetos.

\% de composições de planos irregulares, não perpendiculares e não paralelos ou composições de superfícies curvilíneas (Série1) e de composições de planos retangulares paralelos ou perpendiculares ou, no máximo seções de curvas extrudadas (Série2)

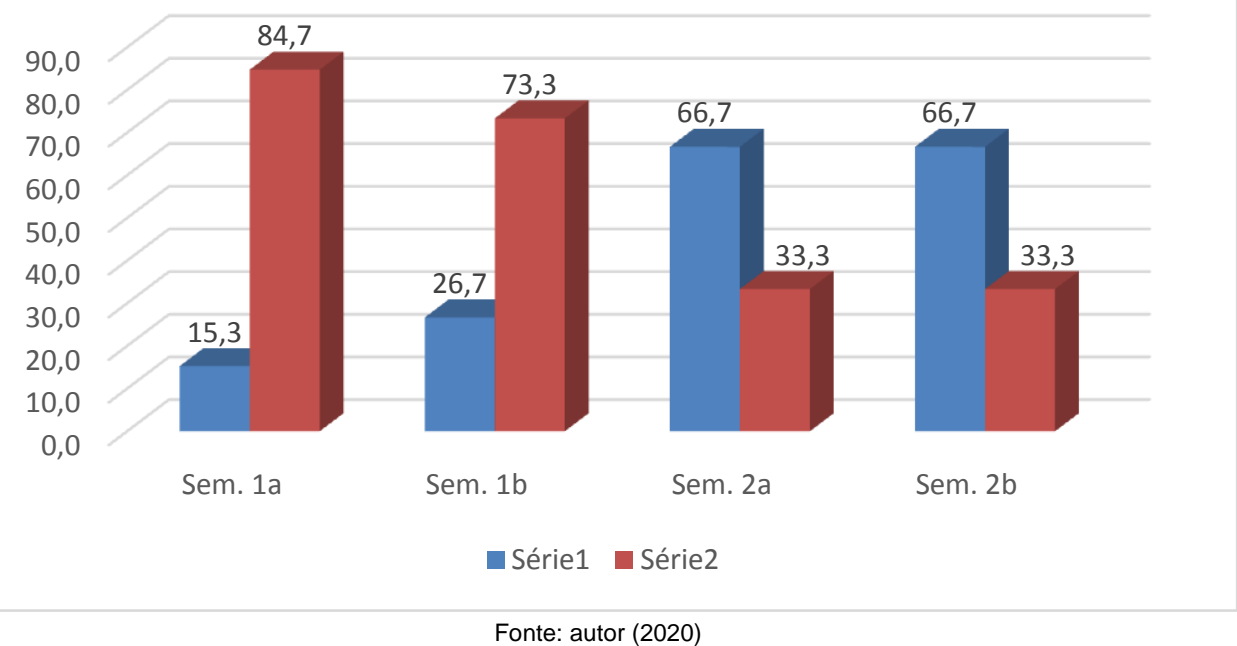

Pode-se observar na Figura 09 uma inversão significativa nas categorias de formas predominantes. Destaque-se que no segundo grupo, Sem. 2a e Sem. 2b, o percentual de formas nas categorias ilustradas pelas Figuras 03 e 06 e Figuras 04 e 07 não poderá nunca ser superior a 66,7 uma vez que um dos três projetos tem como requisito de linguagem arquitetônica exatamente 0 tipo de forma ilustrada pelas Figuras 01 e 05.

Por esta razão, uma terceira avaliação foi feita apenas com o segundo grupo com a seguinte pergunta: em que medida, cada um dos projetos (edifício administrativo, restaurante e pavilhão) satisfez as respectivas condicionantes formais: 1. Integralmente; 2. Parcialmente; 3. Ou não satisfizeram? Os resultados são apresentados na Figura 10. 
Figura 10: Níveis de satisfação dos requisitos de linguagem arquitetônica no segundo grupo.

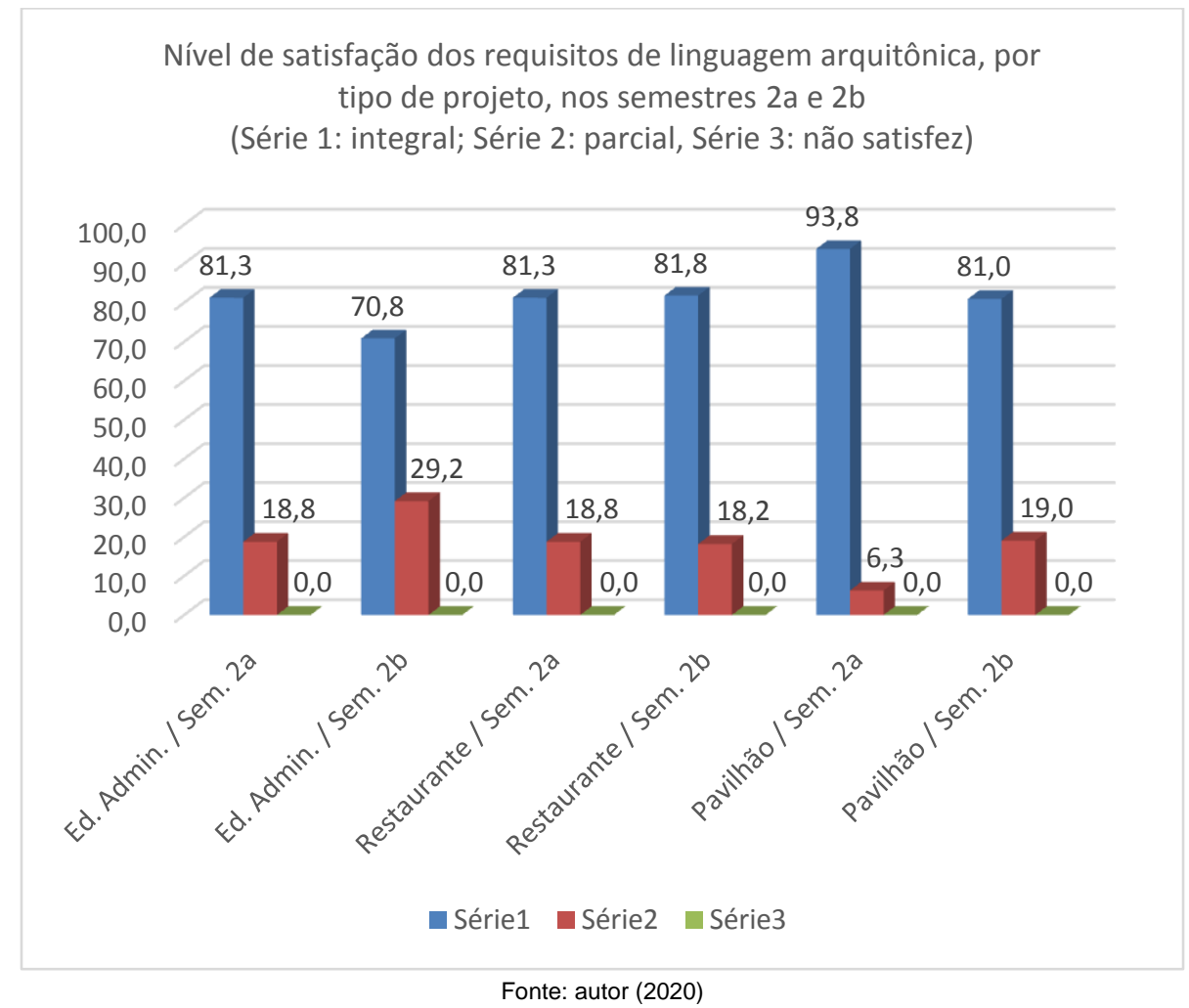

Foi utilizado como critério de distinção entre satisfação integral e satisfação parcial o grau de predominância a que se referem as condicionantes formais descritas no Quadro 01. Assim sendo, a presença em quantidade significativa de elementos pertencentes a linguagens arquitetônicas distintas das condicionantes específicas de um certo projeto faz com ele seja considerado como que satisfazendo parcialmente. Observe-se que nenhum produto deste grupo foi considerado como não satisfazendo as condicionantes específicas de cada projeto. Observe-se ainda que a maioria significativa dos projetos deste grupo satisfizeram integralmente as respectivas condicionantes formais, em um percentual nunca inferior a 70,8\%. A Figura 11, a seguir, apresenta quatro sequências de projetos, cada uma delas elaborada por um mesmo aluno, mas adotando três diferentes linguagens arquitetônicas. 
Figura 11: Quatro sequências de projetos, cada uma delas elaboradas por um mesmo aluno.

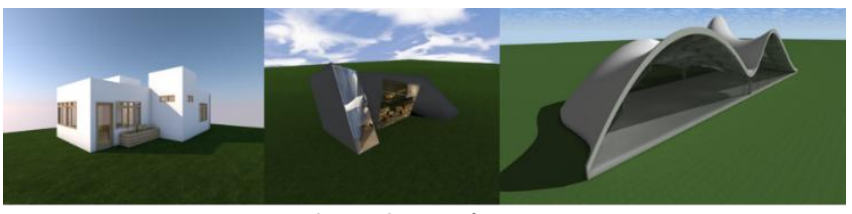

Alexandre Araújo

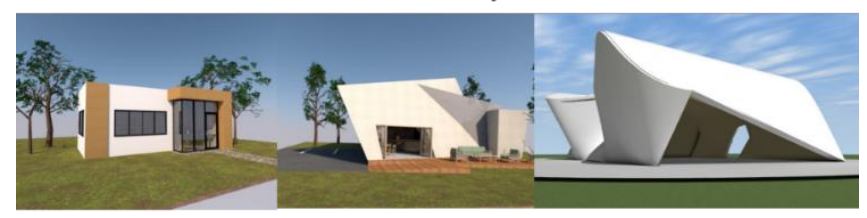

Layanne Soares

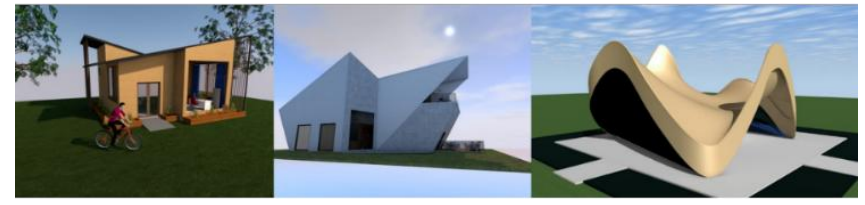

Amanda Marques

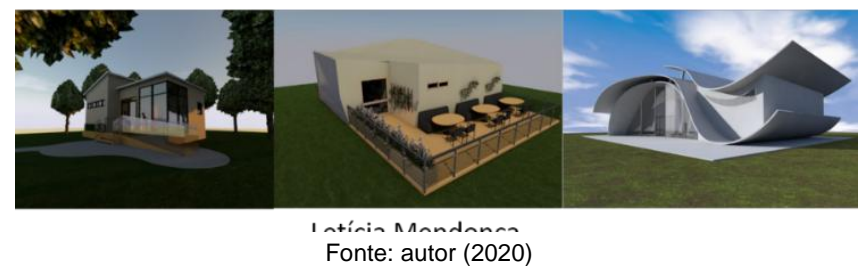

\section{Conclusões}

Após vários anos de ensino empregando essas premissas, os resultados da releitura comparativa dos produtos obtidos são promissores, conforme se pôde observar na sessão anterior. Os projetos resultantes efetivamente respondem, em níveis significativos, às expectativas de linguagem arquitetônica dos clientes. Esta estratégia de ensino também levou à produção de projetos com diferentes linguagens arquitetônicas, ampliando-se a gama de possíveis clientes.

No melhor do conhecimento dos autores deste artigo, a formulação de programas de necessidade, em ensino de projeto, incluindo requisitos ou condicionantes de linguagem arquitetônica constitui-se em uma contribuição original, não encontrando qualquer paralelo na literatura existente.

A categorização da modelagem tridimensional paramétrica descrita na sessão 2.2 por meio de dois paradigmas complementares, sendo um voltado para os processos de criação da forma e o outro para a função que os componentes construtivos vão desempenhar na edificação, também é, no melhor do conhecimento dos autores deste artigo, uma contribuição original.

Por fim, os protocolos apresentados sucintamente na sessão 5, para a utilização de múltiplos modeladores digitais paramétricos ao longo dos processos de projetação, são também, no melhor do conhecimento dos autores deste artigo, uma contribuição original. Estes continuam a ser detalhados e desenvolvidos e deverão ser objeto de futuras publicações.

\section{Agradecimentos}

Agradecemos aos alunos citados na Figura 11 pela gentileza de cederem as imagens de seus projetos.

\section{Referências}

AGIRBAS, A. Use of Digital The Fabrication as a Sketching Tool in the Architectural Design Process - A Case Study, in Martens, B., Wurzer, G., Grasl T., Lorenz, W. E. e Schaffranek, R. (editores), Real Time, Proceedings of the 33rd eCAADe Conference, Vienna University of Technology, Vienna, Austria, volume 2, p. 319-324, 2015. 
AGKATHIDIS, A. e BROWN, A. Tree-Structure Canopy: A Case Study in Design and Fabrication of Complex Steel Structures using Digital Tools, in International Journal of Architectural Computing, School of Architecture, The University of Liverpool, vol. 11, no. 1, p. 7-104, 2013.

ALEXANDER, C., ISHIKAWA, S., SILVERSTEIN, M., JACOBSON, M., FIKSDAHL-KING, I. e ANGEL, S. A Pattern Language - Towns, Buildings, Constructions, Oxford University Press, Nova York, 1977.

AS, I. e SCHODEK, D. Dynamic Digital Representations in Architecture - Visions in Motion, Taylor \& Francis, Nova York e Londres, 2008.

BEIRÃO, J., MATEUS, N. e ALVES, J. S. Modular, Flexible, Customizable Housing and 3D Printed - An experiment in architectural education, in Kepczynska-Walczak, A. e Bialkowski, S. (editores), Computing for a better tomorrow, Proceedings of the 36th eCAADe Conference, Lodz University of Technology, Lodz, Poland, volume 1, p. 381-390, 2018.

BRIDGES, A. The Challenge of Constraints - A Discussion of Computer Applications in Architectural Design, Department of Architecture, University of Strathclyde, Reino Unido, 1991.

COMPETITION.CC, Low Cost House Design Competition, programa de necessidades do concurso (disponível em https://low-costhouse.com/requirements/) acessado em 13 de fevereiro de 2020, publicado em 2020.

CROSS, N. Developments in Design Methodology, The Open University, John Wiley \& Sons, Chichester, Reino Unido, 1984.

CONTROL PLUS SPACE, Hamburg Hybrid Housing Competition, programa de necessidades (disponível em http://www.ctrl-space.net/uploads/9/0/3/4/90348/hamburg_competition_brief.pdf, acessado em 13 de fevereiro de 2020), publicado em 2015.

DINCER, A. E., ÇAĞ)AŞ G. e TONG, H. A Digital Tool for Customized Mass Housing Design, in Thompson, E. M. (editor), Fusion, Proceedings of the 32nd eCAADe Conference, Department of Architecture and Built Environment, Faculty of Engineering and Environment, Newcastle upon Tyne, Reino Unido, 10-12, Volume 1, pp. 201-211, 2014.

FLEMMING, U. Syntactic Structures in Architecture: Teaching Composition with Computer Assistance, in CAAD futures Digital Proceedings, 1989.

IBRAHIM, M., BRIDGES, A., CHASE, S., BAYOUMI, S. e TAHA, D. Grammatically Thinking Summing up the teaching of the first year with a comprehensive grammatical project, in CAAD / Innovation / Practice, 6th International Conference Proceedings of the Arab Society for Computer Aided Architectural Design, ASCAAD, Manama, Bahrain, p. 689-698, 2012.

IWAMOTO, L. Digital Fabrications - Architectural and Material Techniques, Princeton Architectural Press, Nova York, 2009.

KOLAREVIC, B. Digital Morphogenesis, in Kolarevic, B. (editor), Architecture in the Digital Age Design and Manufacturing, Taylor \& Francis, Nova York e Londres, p. 11-28, 2005a.

KOLAREVIC, B. Digital Production, in Kolarevic, B. (editor), Architecture in the Digital Age - Design and Manufacturing, Taylor \& Francis, Nova York e Londres, 29-54, 2005b.

KOLAREVIC, B. e KLINGER, K. Manufacturing Material Effects - Rethinking Design and Making in Architecture, Taylor \& Francis, Nova York e Londres, 2008. 
LAWSON, B. How Designers Think - The Design Process Demystified, Architectural Press, Elsevier, Londres, Reino Unido, 2005.

LOGAN, B. The Structure of Design Problems, tese de doutorado, University of Strathclyde, Reino Unido, 1987.

MITCHELL, W.J. Roll over Euclid: How Frank Gehry Designs and Builds. In: Gehry, F.O., Ed., Frank Gehry, Architect, Guggenheim Museum Publications, New York, 352-363, 2001.

MITCHELL, W. J. The Logic of Architecture: Design, Computation, and Cognition, The MIT Press, Cambridge, MA, 1990.

MITCHELL, W. J. e MCCULlOUGH, M. Digital Design Media, Van Nostrand Reinhold, Nova York, 1995.

MITCHELL, W. J. T. Representation, in Lentricchia, F. e McLaughlin, T., Critical Terms for Literary Study, The University of Chicago Press, Chicago e Londres, 1995.

MOUSSAVI, F. The Function of Form, Actar and Harvard University Graduate School of Design, Nova York, 2009.

MUSTOE, J. E. H. Artificial Intelligence and its Application in Architectural Design, tese de doutorado, University of Strathclyde, Reino Unido, 1990.

RIBA, Taylor Wimpey 2020 Design Competition, programa de necessidades do concurso (disponível em http://www.ribacompetitions.com/taylorwimpey/downloads/TW_Project2020_Brief.pdf), acessado em 13 de fevereiro de 2020, publicado em 2016.

ROBBINS, E. Why Architects Draw, MIT Press, Cambridge, 1994.

SACKS, R., EASTMAN, C., LEE, G. e TEICHOLZ, P. BIM Handbook - A Guide to Building Information Modelling for Owners, Designers, Engineers, Contractors and Facility Managers, John Wiley \& Sons, New Jersey, 2018.

SAKAMOTO, T. e FERRÉ, A. From Control to Design - Parametric / Algorithmic Architecture, Ingoprint SL, Barcelona e Nova York, 2008.

SILVA, N. F., BRIDGES, A. H., LIMA, E. M., MORAIS, H. R. A. e JÚNIOR, F. A. S. A indústria da Construção Civil está pronta para a Fabricação Digital e a Customização em Massa? Uma pesquisa sobre um caso brasileiro, Anais do SIGraDi, Universidade Mackenzie, São Paulo, Brasil, 2009.

SPILLER, N. Digital Architecture Now, Thames \& Hudson, Nova York, 2009.

STINY, G. Introduction to Shape and Shape Grammars, in Environment and Planning B, volume 7, p. 343-351, 1980.

WOODBURY, R. Elements of Parametric Design, Routledge / Taylor \& Francis, Nova York e Londres, 2010.

YESSIOS, C. Is There More to Come? in Kolarevic, B. (editor), Architecture in the Digital Age Design and Manufacturing, Taylor \& Francis, Nova York e Londres, 2005.

ZEVI, B. Architecture as Space - How to Look at Architecture, Horizon Press, Nova York, 1957. 